WIDER Working Paper 2017/105

\title{
Gender identity and female labour supply in Brazil
}

Karen Codazzi, ${ }^{1}$ Valéria Pero, ${ }^{1}$ and André Sant'Anna ${ }^{2}$

April 2017

United Nations University World Institute for Development Economics Research 
Abstract: Over the last half-century, the role of women in society has changed substantially. However, the gender income gap and the difference in labour force participation persist. Akerlof and Kranton introduce the concept of identity from sociology and social psychology at the economic analysis; based on this we search less traditional factors for understanding this persistence. We extend the analysis proposed by Bertrand et al. for Brazil. Specifically, we analyse the impact of gender identity, focusing on the prescription that 'a man should earn more than his wife' on social and economic results. Based on the Censuses for 1991, 2000, and 2010 we observed that for only 7 per cent of married couples does the wife earn more than her husband. We found evidence that the wives with greater probability of earning more than their husbands are less likely to participate in the labour force. Once she does participate in the labour force, she has a higher probability of earning less than her potential income, working fewer hours, and having an informal job.

Keywords: female labour force, gender gap, identity, labour market

JEL classification: J12, J16, J22

${ }^{1}$ Economics Institute of the Federal University of Rio de Janeiro, Rio de Janeiro, Brazil; ${ }^{2}$ Economics Institute of the Federal University of Rio de Janeiro, and the Brazilian Development Bank, Rio de Janeiro, Brazil; corresponding author: vpero@ie.ufrj.br This study has been prepared within the UNU-WIDER project on 'Gender and development'.

Copyright (C) UNU-WIDER 2017

Information and requests: publications@wider.unu.edu

ISSN 1798-7237 978-92-9256-329-5

Typescript prepared by Gary Smith.

The United Nations University World Institute for Development Economics Research provides economic analysis and policy advice with the aim of promoting sustainable and equitable development. The Institute began operations in 1985 in Helsinki, Finland, as the first research and training centre of the United Nations University. Today it is a unique blend of think tank, research institute, and UN agency — providing a range of services from policy advice to governments as well as freely available original research.

The Institute is funded through income from an endowment fund with additional contributions to its work programme from Denmark, Finland, Sweden, and the United Kingdom.

Katajanokanlaituri 6 B, 00160 Helsinki, Finland

The views expressed in this paper are those of the author(s), and do not necessarily reflect the views of the Institute or the United Nations University, nor the programme/project donors. 
Recent decades have witnessed great changes in the roles of women in society. In spite of the recent progress, Brazil remains a country with important disparities between men and women. The issue of gender inequality is not restricted to the economic domain: domestic violence was until recently considered a minor crime. Only as of 2006, under the Maria da Penha Act (Act 11340/2006), have victims been entitled to protection (Cerqueira et al. 2015). As of 2013 labour rights have been fully expanded to domestic workers, ${ }^{1}$ of which more than 90 per cent are women (Costa et al. 2016).

From the economical viewpoint, women achieved important gains. The major transformation was the sharp increase in female participation in the labour market. It has grown 8.5 percentage points (p.p.) from 1992 to 2012, while this figure among men has fallen 5.9 p.p. over the same period (Barbosa 2014). Further, there has been a reduction in the gender wage gap: in 1995 women earned, on average, only 53 per cent of men's income. As of 2014, this gap has reduced: women's average income was 70 per cent that of men (Pinheiro et al. 2016). A major reason for this reduction in the wage gap is the sharp decline in the educational gap. As a matter of fact, as happened in some developed countries, the educational gap in Brazil has reversed-on average, women now have more years of education than do men (Beltrão and Alves 2013). In addition, some policies with the aim of eliminating gender discrimination in the labour market have contributed to the narrowing of the wage gap (Barros and Mendonça 1996).

In spite of this recent progress, there remains a substantial difference in earnings between men and women, as well as a difference in labour force participation. When considering the earnings differences, most studies divide the gender wage gap estimates into a portion 'explained' by productive characteristics (e.g. education and experience) and a residual portion designated as 'wage discrimination' since it is the wage difference between men and women who have identical observable characteristics. In Brazil, Matos and Machado (2006) showed an increase in this residual 'wage discrimination' portion over the last decade. However, the part explained by observable variables such as education and experience has become more favourable for women. Thus, even with the tendency to increase the residual portion, the wage differential fell during the analysed period. Hoffmann et al. (1999) analysed the impact of occupational segregation on the wage differential, comparing the gender wage gap between and within occupations. They found that wage discrimination in Pernambuco occurs mainly within occupations. In São Paulo, on the other hand, the decomposition of wage discrimination shows that it occurs both between and within occupations.

These results lead to explanations as presented in the Goldin's (2014) analysis of gender equality. The gender wage gap within the occupation type is responsible for a large portion of the overall wage gap, and varies significantly by occupation. The proposed explanation is based on the relationship between occupations earnings and breakdown of time worked. That is, a more flexible schedule is often compensated by higher remuneration, as in corporate, financial, and legal occupations.

A compensating differentials model explains wage differences by the costs flexibility. The higher or lower costs of time flexibility and the underlying

\footnotetext{
${ }^{1}$ Constitutional Amendment 72/2013.
} 
causes of nonlinearity of earnings with respect to time worked. Much has to do with the presence of good substitutes for individual workers when there are sufficiently low transactions costs of relaying information. (Goldin 2014: 1116)

Thus, the difference in the value of time between men and women may be the root of the persistence of negative results regarding the role played by women in the labour market. Although the working hours gender gap is reducing over time in Brazil, the differences in weekly hours devoted to household chores between men and women are huge: 10 hours for men and 20 for women. This difference is even higher for couples. Therefore, it is necessary to search for less traditional factors within economic theory in order to understand these persistent gender gaps. This paper is based on the idea of identity, borrowed by Akerlof and Kranton (2000) from sociology and social psychology.

The theory of identity developed by the authors contrasts with the theory of individuals' preferences, since identity and social norms derive from the social context. Thus, the introduction of identity into an economic model of individual preferences produces a theory of the decision-making process in which the social context is relevant. It is important to note that in identity theory the individual's 'choices' are not always rational in the usual sense, as Akerlof and Kranton (2000: 719) clarify: "We use the verb "choose" advisedly. We do not presume one way or another that people are aware of their own motivations, as in standard utility theory which is agnostic as to whether an individual shopper is aware or not of the reasons for her choices.'

The authors define identity as a 'person's sense of self. This sense is related to a social category to which a person ascribes. These social categories can be fixed and predetermined, such as sex, or, in other cases, the person can choose the identity, such as between smokers and non-smokers.

Each social category has its own forms of behaviour. In this context, if someone does not behave as expected by a certain social category, she suffers a loss of identity, affecting her well-being. Going further, someone's own identity may be affected by others' violation of social expectations. Thus, behaviours 'out of the norm' have externality effects. ${ }^{2}$

One important aspect of a person's identity is his or her gender. Men and women have long been faced with different prescriptions, such as 'men should be the breadwinners while women should take care of the household', or its more modern version that states that 'a man should earn more than his wife'. Bertrand et al. (2015) suggest that those identity-related prescriptions impact the labour market choices of married women.

Indeed, data from the World Value Survey shows that 16.8 per cent of Brazilians agree with the statement that 'when jobs are scarce men should have more right to a job than women', and 33.5 per cent of Brazilians agree with the affirmation 'if a woman earns more than her

\footnotetext{
${ }^{2}$ Akerlof and Kranton (2010) present many examples in this sense. Given the aims of this paper, the most interesting one refers to the entry of women into jobs mainly occupied by males.

${ }^{3}$ This percentage is higher in other Latin American countries-22.4 per cent in Colombia and 17.6 per cent in Chile_-and smaller in developed countries such as the United States and Sweden, where only 5.7 per cent and 2 per cent agree with the statement, respectively.
} 
husband, it is almost certain to cause problems'. ${ }^{4}$ It seems that it makes sense to assume, as proposed by Bertrand et al. (2015), that there is a social norm related to gender identity which states that 'a woman should not earn more than her husband'.

Based on this framework, Bertrand et al. (2015) present an ingenious way to analyse this norm using US data on relative income within households. The authors show that the frequency of weddings has a discontinuity when the share of the household income that comes from the wife is higher than 0.5. Put simply, there is a sharp drop in weddings when the wife earns more than the husband. Using 2008-10 American Community Survey data on young couples, the authors conclude that there is a discontinuity in the distribution of relative income at 0.5 , which suggest that couples avoid situations in which the wife earns more than her husband, and provides unusually direct evidence of a gender norm.

In order to clarify this link between marriage rate and the relative income in the household, the authors analyse the hypothesis that women in the marriage market with a higher probability of earning more than a man are less likely to marry. ${ }^{5}$ Using data from the US Census Bureau from 1970 to 2010, the authors estimated the impact on the marriage rate of the probability that a woman earns more than a man by marriage market. ${ }^{6}$ They find results that fit the hypothesis: in a given marriage market, when a randomly chosen woman is more likely to earn more than a randomly chosen man, the marriage rate declines.

Going further, the authors analyse the hypothesis that within couples, if the wife's potential earnings are likely to exceed the man's, the wife's labour supply is lower. Also using US Census data, Bertrand et al. (2015) show that married woman that have higher probability of earning more than their husbands are less likely to be in the labour market, both in the extensive and intensive margins. This result, which is totally counter-intuitive for a standard utility model, can be explained by the identity framework. Finally, if the wife earns more than the husband, there is a higher probability of divorce and the wife's household production increases, as if to compensate.

After this first empirical test of the identity theory in economics, Wieber and Holst (2015) and Hederos Eriksson and Stenberg (2015) have replicated the analysis in two high-income countries: Germany and Sweden, respectively. For Germany, Wieber and Holst (2015) find the same shape of the distribution of relative income, with a discontinuity when the woman earns more than the man in the marriage. Hederos Eriksson and Stenberg (2015), regarding Sweden, do not find this break in the distribution of households' relative income. Wieber and Holst (2015) have also analysed labour supply of married women, but did not find results similar to those presented by Bertrand et al. (2015) for the United States.

In this paper we analyse the effects of this social norm on labour market outcomes in Brazil. As far as we know, this is the first analysis of the role of gender identity on female labour supply in a developing country. By looking at Brazil, we provide results based on a country traditionally more biased in favour of men than the previously discussed ones. We use data

\footnotetext{
${ }^{4}$ In Brazil, 1,486 people were interviewed. The percentage of people that agree with the affirmative varies considerable by country: 43.8 per cent in Colombia, 33.7 per cent in Chile, 12.4 per cent in the United States, and 11.5 per cent in Sweden. For further details, see WVSA (2014).

${ }^{5}$ Bertrand et al. (2015) define marriage markets based on the patterns observed in that individuals tend to marry people of similar age, education, and race.

${ }^{6}$ The value of that variable was estimated at marriage market level, based on the relative income of women and men that belong to the same marriage market.
} 
from the Brazilian Population Census for the years 1991, 2000, and 2010. At first, we analyse the distribution of relative income within households and find a similar pattern as present in the United States and Germany. In only 7 per cent of couples does the woman earn more than the man.

Following the analysis, we investigate the effects of gender identity-related social norms on female labour supply. ${ }^{7}$ Results point to a negative relationship between female labour force participation and the probability that a woman would earn more than her husband, given her observable characteristics. In addition to this extensive margin adjustment, there are also effects on the intensive margin: the higher the probability of a woman earning more than her husband, the higher the gap between actual and potential wages and the fewer hours the woman offers in the labour market.

Furthermore, in developing countries with strict labour institutions and loose enforcement, as is the case in Brazil, there is an additional form of adjustment: informal jobs. Therefore, we show that there is a positive relationship between the probability of a wife earning more than her husband and participation in the labour market via informal jobs.

Our results are consistent with the recent literature on gender identity that is beginning to flourish (Bertrand et al. 2015; Hederos Eriksson and Stenberg 2015; Wieber and Holst 2015). This paper belongs, therefore, to a recent research agenda that brings an empirical basis to the concept of identity brought to economics by Akerlof and Kranton (2000), especially when it refers to gender inequality. Therefore, this literature contributes to aspects beyond the purely economical to understand distinct causes of horizontal inequalities, and introduces the possibility of discussing aspects that go from recognition to redistribution (Fraser 1995). ${ }^{8}$ Finally, by bringing the analysis to a developing country, this paper sheds light on some aspects of labour supply adjustments that are not common in developed countries. More specifically, the analysis on female labour participation in informal markets allows us to better understand how it occurs in a context in which labour market functioning is very distinct from that in developed countries.

\section{$2 \quad$ A simple model}

Akerlof and Kranton (2000) introduce identity, as well as their prescriptions, into the model of individual choices based on utility maximization. Formally, the model developed by the authors can be expressed by the utility function $U_{j}$, which depends on $j$ 's identity $I_{j}$, on the usual vector of $j$ s actions $a_{j}$ and on the actions of other people $a_{j}$ :

$$
U_{j}=U_{j}\left(a_{j}, a_{-j}, I_{j}\right)
$$

As analysed before, $j$ s identity also depends, first of all, on $j$ s assigned social category $c$, and the corresponding $\mathrm{P}$ prescriptions that define how the members of that social category

\footnotetext{
${ }^{7}$ In the Appendix we evaluate how the relative income affects marriage formation. As in Bertrand et al. (2015), our results show the importance of relative income for the frequency of marriages.

${ }^{8}$ Stewart (2005) discusses how horizontal inequalities remain a neglected dimension in the discussions on development.
} 
should behave in specific situations. Also, the degree to which j's characteristics match the ideal for $j$ 's social category $\varepsilon_{j}$. Besides that, $j$ s identity also depends on $a_{j}$ and $a_{j}$ :

$$
I_{j}=I_{j}\left(a j, a-j, c_{j}, \varepsilon_{j}, \mathrm{P}\right)
$$

So, in the simplest scenario, $j$ maximizes her utility taken as given $a_{j}, c_{j}, \varepsilon_{j}$, and $\mathrm{P}$.

In the gender identity context, suppose a simple model in which the female's utility is given by:

$$
U_{f}=\left\{\begin{array}{lr}
a \cdot y_{f}-t\left(y_{f}-y_{m}\right) \text { if } y_{f}>y_{m} \\
a . y_{f} \text { if } y_{f} & <y_{m}
\end{array}\right.
$$

where $y_{f}$ is the woman's income, $y_{m}$ is the man's income, and $a$ and $t$ are parameters. It is easy to see that there is a discontinuity in the woman's utility if her income exceeds her husband's. This comes from the identity loss that comes from deviating from the social norm. Indeed, if $t>a, U_{f}$ declines when $y_{f}>y_{m}$.

Though very simple, this model allows us to understand how the social norm analysed in this paper can affect female labour market decisions. As relative income exceeds 0.5 , the wife's marginal utility declines, since there is an identity loss due to the non-compliance with the social norm. This entails effects on the decisions regarding the woman's participation in the labour market. These decisions can reflect adjustments in the intensive margin-by earning less than her potential or working fewer hours - or can be even more radical and lead to dropping out of the labour market.

\section{Data}

We use data from three different population censuses, as published by the Brazilian Institute of Geography and Statistics (IBGE): 1991, 2000, and 2010. The Demographic Census is a survey conducted by the IBGE once every 10 years, in which all households in the Brazilian territory are visited. The Census provides a population count and collects basic information from residents, such as age and gender.

At the time of the Census, the IBGE conducts a more detailed interview with a large random sample of households, in which it investigates sociodemographic characteristics of the residents (such as schooling and income), physical characteristics of the place of residence (e.g. walling materials), and possession of goods (such as a refrigerator or car). As the Census interview is at the household level, we can identify all individuals per household.

We used two samples from this more detailed Census database. First, we used a sample with all individuals aged between 18 and 65 years to calculate the parameters of income distribution by demographic group. Than we used a sample selected from the Census microdata that includes only private households composed of the head of household, their spouse, and children if present. The sample is restricted to heterosexual couples in which both man and woman are aged between 18 and 65 years. 


\section{$4 \quad$ Relative income distribution within households}

In order to understand the effects of the distribution of relative income within households, we start our analysis with young couples in Brazil, in which both individuals are between 18 and 35 years old. We use data from the 1991, 2000, and 2010 population censuses published by the IBGE. The focus on young couples allows emphasis of the impacts of gender identity in marriage formation.

Relative income is defined as the ratio between the wife's income and the income received by both wife and husband, as shown in the formula:

$$
\text { relative } \text { income }_{i}=\frac{\text { wife }_{\text {income }}}{\text { wife }_{\text {income }}+\text { husband } \text { income }_{i}}
$$

where the subscript $i$ refers to the couple. The Census has many couples with relative income exactly equal to 0.5 . This does not seem plausible and might be related to the research method, which is based on a self-statement of income (Bertrand et al. 2015). Thus, some of these observations have been redistributed following a kernel triangular function.

Figure 1 displays the relative income distribution for each year: 1991, 2000 and 2010, ${ }^{9}$ respectively. It can be seen that the three distributions have the same pattern. They increase up to 0.5 , which is in line with marriage theories that assert that people have a higher probability of marrying others that share common features. ${ }^{10}$ However, as the relative income reaches 50 per cent, there is an abrupt break in the distribution. This suggests the existence of an aversion to the situation in which the wife earns more than her husband, as proposed by Bertrand et al. (2015).

\footnotetext{
${ }^{9}$ For the construction of the graphic we deleted the observations for which the relative income was 0 , which means that the wife has no income. The sample deleted represented 59 per cent of the total married couples.

${ }^{10}$ See, for example, Becker (1973).
} 


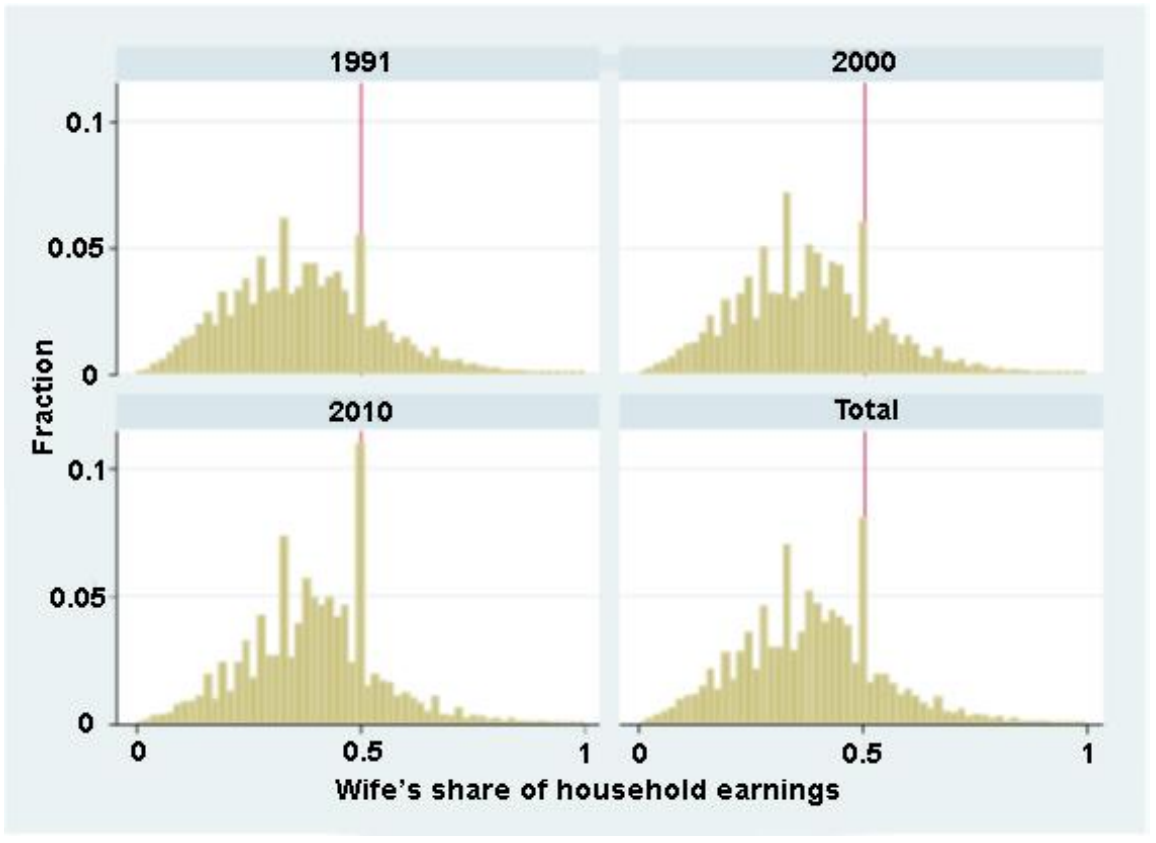

Source: authors, based on Census data.

The pattern present in Brazil is similar to the one found by Bertrand et al. (2015) for the United States and by Wieber and Holst (2015) for Germany. This result suggests that gender identity is an important factor when it comes to understanding marriage formation and to explaining the shape of relative income distribution within households. Considering the aggregate of the three years of Census data, in only 6.6 per cent of the couples aged between 18 and 35 years old did the wife earn more than her husband. In 1991, this figure was only 5 per cent; it increased to 8.4 per cent in 2010.

Considering a broader sample of couples, with ages between 18 and 65 years old, in 7 per cent of couples the wife earned more than her husband. This ratio evolved from 5 per cent in 1991 to 10 per cent in 2010.

These results suggest a potential correlation between two tendencies observed in the last decades: (1) an increase in female participation in the labour market, with a corresponding decrease in the gender wage gap, and (2) a decrease in the proportion of the population who got married. Indeed, while in Brazil in the 1970s there were 13 marriages per 1,000 inhabitants older than 15 years, this rate dropped to 7 per 1,000 inhabitants in the 2000s.

A possible explanation for these phenomena is related to social norms linked to gender identity. After all, if couples believe there will be trouble in a relationship in which the woman earns more than the husband, higher female labour force participation and higher earnings for women would make marriage less attractive and, as a consequence, less common.

\section{Labour market and relative income}

One potential explanation for that sharp drop in the wife's share of household earnings is that wives distort their labour supply in order not to violate gender identity norms. 
Akerlof and Kranton (2010) argue that gender identity and the social norms for each gender impact the decisions that occur within the household on issues such as: who should work; how many hours each should offer on the labour market; and how to divide the household chores and childcare. According to the conventional models of family decision-making, similar to a 'comparative advantage' model, the partner who has relative advantage at obtaining income will go out to work, while whoever is relatively better in domestic production will be responsible for household chores. This theory assumes a symmetrical result: the person who works outside performs fewer domestic tasks and vice versa.

The authors argue that this is not the pattern observed in the United States or other countries, including Brazil, as was shown by the results of IBGE's time-use research, which reveal that home-based care and household activities are still carried out mostly by women, while men maintain a stronger presence in the labour market.

In this section we analyse the consequences of gender identity for the decisions of families in relation to the labour market, again focusing on the social norm that 'a man must earn more than his wife'.

\subsection{Female labour market participation}

One of the most traditional ways to follow a behaviour pattern based on gender identity is considering the woman as responsible for household activities and childcare while the man takes the provider position at home, ensuring the livelihood of the family (Bertrand 2011). Thus, the purpose of this section is to analyse how the norms associated with the roles of each gender impact the decision of women to participate in the labour market.

The data source to analyse these issues was, as in the previous section, the Brazilian Demographic Census for the years 1991, 2000, and 2010. The sample selected from the Census microdata includes only private households composed of the head of household and spouse, with or without children. The sample is restricted to heterosexual couples in which both are between 18 and 65 years old.

In order to capture the effect of the social norm that 'a man must earn more than his wife', we created a variable that is the probability that a woman earns more than her husband. It is worth noting that this variable is measured at the couple level, and not at the marriage market level as in the previous section. The purpose here is to observe the impact of that probability on female participation in the labour market.

We estimate this probability based on the wage distribution of each woman's demographic group. First, we defined 200 demographic groups combining the following characteristics: age (four age groups: 18-29, 30-39, 40-49, and 50-65 years old); educational level (five schooling levels: without schooling or incomplete primary education, primary education complete or high school incomplete, complete high school and incomplete undergraduate, complete undergraduate, and more); region of residence (five regions: North, Northeast, Southeast, South, and Midwest); and race (two groups: white-including white and yellow; and black-including blacks, mixed race, and Indians). For each demographic group we calculate 20 quantiles of women's income for each year. ${ }^{11}$ Therefore, for every couple we calculate the probability that a woman would earn more than her husband by comparing the

\footnotetext{
${ }^{11}$ We considered only women with positive income-that is, who are in the workforce and employed with remuneration.
} 
average income of each of the 20 quantiles of women's income distribution with her husband's wage, creating an indicator function that takes 1 if the income of the quantile is greater than her husband's, and 0 otherwise.

Finally, we calculate the probability that the woman earns more than her husbandPrWifeEarnsMore - by averaging these indicator functions with the following formula:

$$
\text { PrWifeEarnsMore }_{i}=\frac{1}{20} \times \sum_{p} 1 \text { if }_{i}^{P}>\ln \text { HusbIncome }_{i}
$$

where $w_{i}^{p}$ is the average of $P$ quantile of women's wages in the demographic group of each year and the subscript $i$ indicates the couple. We use the logarithm of hourly income as a measure of income to calculate the probability. This variable was created based on the estimates proposed by Bertrand et al. (2015), adapted to the data available in the Brazilian Census.

This section aims to estimate the impact of the probability that the woman earns more than her husband on a number of outcome variables, which will be displayed below. In this subsection, the variable of interest is a variable dummy indicating whether or not the woman that is part of couple $i$ participates in the labour market ( 1 if the woman is employed, 0 otherwise).

The causal effect estimation of PrWifeEarnsMore $e_{i}$ on women's participation in the labour market can be obtained by estimating the linear model probability as follows:

$$
\begin{aligned}
& \text { wife LFP }_{i}=\beta_{0}+\beta_{1} \times \text { PrWifeEarnsMore }_{i}+\beta_{2} \times \ln \text { HusbIncome }_{i}+\alpha \times w_{i}^{p}+ \\
& \beta_{3} \times W_{i}^{p}+\varepsilon_{i}
\end{aligned}
$$

Where ln HusbIncome $e_{i}$ is the logarithm of the husband's income, $w_{i}^{p}$ is a control for the woman's potential income for each quantile. $X_{i}$ is a vector of controls as a time-fixed effect, region-fixed effect, the woman's and man's age group, educational group, and race.

In the base model estimation the $\beta_{1}$ is equal to $-0.132(p<0.01)$. This estimate shows that an increase of 10 p.p. in the probability that the woman earns more than her husband decreases her chance to participate in the labour market by 1.32 p.p., as can be seen in column 1 of Table 1. 
Table 1: Relative income and female labour participation

\begin{tabular}{lcccccc}
\hline Variables & $\begin{array}{c}(1) \\
\text { wifeLFP }\end{array}$ & $\begin{array}{c}(2) \\
\text { wifeLFP }\end{array}$ & $\begin{array}{c}(3) \\
\text { wifeLFP }\end{array}$ & $\begin{array}{c}(4) \\
\text { wifeLFP }\end{array}$ & $\begin{array}{c}(5) \\
\text { wifeLFP }\end{array}$ & $\begin{array}{c}(6) \\
\text { wifeLFP }\end{array}$ \\
\hline PrWifeEarnsMore & $-0.132^{* * *}$ & $-0.132^{* * *}$ & $-0.128^{* * *}$ & $-0.031^{* * *}$ & $-0.035^{* * *}$ & $-0.080^{* * *}$ \\
& $(0.0018)$ & $(0.0018)$ & $(0.0018)$ & $(0.0045)$ & $(0.00 .32)$ & $(0.0040)$ \\
Additional controls & & & & & & \\
Cubic in In Husblncome & None & Yes & Yes & Yes & Yes & Yes \\
anyChild(ren) & None & None & Yes & Yes & Yes & Yes \\
Sample restriction? & None & None & None & 1991 & 2000 & 2010 \\
Observations & $2,008,565$ & $2,008,565$ & $2,008,565$ & 457,534 & 611,571 & 939,460 \\
R-squared & 0.078 & 0.078 & 0.080 & 0.102 & 0.100 & 0.066 \\
Mean of WifeLFP & 0.38 & 0.38 & 0.38 & 0.26 & 0.38 & 0.46 \\
\hline
\end{tabular}

Notes: robust standard errors in parentheses. ${ }^{* \star *} p<0.01,{ }^{\star *} p<0.05,{ }^{*} p<0.1$.

The PrWifeEarnsMore is based on the distribution of the wife's actual earnings.

Source: authors.

As the husband's income can impact the utility of the household in a non-linear way, we include in our model the cubic of the husband's income logarithm. The estimate of $\beta_{1}$ remains constant and statistically significant with the inclusion of control variables, as we see in column 2 , in which the estimate of $\beta_{1}$ is $-0.132(p<0.01)$.

Moreover, we have included a control variable that indicates whether a woman has children or not and the estimate of $\beta_{1}$ also remained steady and statistically significant with a $\beta_{1}$ of $-0.128(p<0.01)$, as we can see in column 3 . The fact that our estimate appears to be stable to the inclusion of other controls suggests that the negative value of $\beta_{1}$ is not due to omitted variable bias (Altonji et al. 2005; Murphy and Topel 1990). These results support our hypothesis that the social norm that 'a man should earn more than his wife' adversely impacts the participation of women in the labour market.

Table 1 presents the estimation of $\beta_{1}$ separately for each year in columns 4 , 5 , and 6 . The estimate of $\beta_{1}$ ranges over the decades, which is potentially important as factors affecting women's participation in the labour market may vary over time. The estimated coefficients express a negative and statistically significant relationship between the probability that the woman earns more than her husband and female participation in the labour market for every year.

\subsection{Potential and effective wage differential}

The decision to not participate in the labour market can be a very costly way to restore traditional gender roles. The woman may instead participate in lower-paid occupations that do not threaten her husband's position as the household provider. In this section we seek evidence for this behaviour by analysing the impact of relative income on the difference between a woman's effective and potential earnings.

In this second analysis, the sample is more restricted than in the previous section in order to keep only couples in which women are employed with positive remuneration, in order to emphasize the wage distortions of women in the labour market. Following Bertrand et al. (2015), we estimate a woman's potential earnings by the income distribution in the demographic group the woman belongs to.

Considering the couple $i$, we calculate the wage gap of women as: 


$$
\text { WageGap }_{i}=\frac{\text { wifeIncome }_{i}-\text { wifePotential }_{i}}{\text { wifeIncome }_{i}}
$$

where wifePotential is the potential earnings of women, which is the mean of women's potential wage distribution defined as in the previous section-that is, the average income distribution of that woman's demographic group.

We use for this analysis the same specification model described before, but as the dependent variable in this model is continuous, we estimate the impact of PrWifeEarnsMore in $_{i}$ the wage gap (Wage Gapi) using an ordinary least squares (OLS) model, as follows:

$$
\begin{aligned}
& \text { WageGap }_{i}=\beta_{0}+\beta_{1} \times \text { PrWifeEarnsMore }_{i}+\beta_{2} \times \ln \text { Husblncome }_{i}+\alpha \times w_{i}^{p}+ \\
& \beta_{3}+X_{i}+\varepsilon_{i}
\end{aligned}
$$

where the control variables are the same as described in the previous model.

Table 2 shows the results of the estimates. Column 1 presents a $\beta_{1}$ estimate of -0.437 $(\phi<0.01)$ for the basic model described previously. The estimate of $\beta_{1}$ remains constant and statistically significant with the inclusion of the cubic of ln HusbIncome $e_{i}$ and with a dummy for having a child, as can be seen in columns 2 and 3, which show, respectively, estimates of $\beta_{1}$ with values $-0.431(p<0.01)$ and $-0.433(p<0.01)$. These results show that an increase of 10 p.p. in the probability that the woman earns more than her husband widens the gap between actual and potential earnings, on average, by 4.3 p.p.

Table 2: Relative income and wife's income gap

\begin{tabular}{lcccccc}
\hline Variables & $(1)$ & $(2)$ & $(3)$ & $(4)$ & $(5)$ & $(6)$ \\
& wageGap & wageGap & wageGap & wageGap & wageGap & wageGap \\
\hline PrWifeEarnsMore & $-0.437^{\star \star *}$ & $-0.431^{\star \star \star}$ & $-0.433^{\star \star \star}$ & $-0.057^{\star \star \star}$ & $-0.726^{\star \star \star}$ & $-0.345^{\star \star \star}$ \\
& $(0.0592)$ & $(0.0589)$ & $(0.0588)$ & $(0.0153)$ & $(0.0138)$ & $(0.0296)$ \\
Additional controls: & & & & & & \\
Cubic in In Husblncome & None & Yes & Yes & None & None & None \\
anyChild(ren) & None & None & Yes & None & None & None \\
Sample restriction? & None & None & None & 1991 & 2000 & 2010 \\
Observations & $2,001,289$ & $2,001,289$ & $2,001,289$ & 414,473 & 868,851 & 717,965 \\
R-squared & 0.01 & 0.01 & 0.01 & 0.24 & 0.01 & 0.045 \\
Mean of WageGap & -0.4 & -0.4 & -0.4 & -0.13 & -0.53 & -0.38 \\
\hline
\end{tabular}

Notes: robust standard errors in parentheses; ${ }^{* *} p<0.01,{ }^{* *} p<0.05,{ }^{*} p<0.1$.

Source: authors.

Columns 4, 5, and 6 of Table 2 present the $\beta_{1}$ of each decade. The estimated $\beta_{1}$ varies over time, but the signal of the relationship between PrWifeEarnsMore and the wage gap is the same and remains statistically significant through the years analysed.

\subsection{Relative income and wife's working hours}

As we say in the previous section, not participating in the labour market can be very costly, and because of that, some wives, instead of leaving the labour force, may choose ways to become flexible in their labour supply. In the previous section we analysed this flexibility through the income gap between the realized and potential income of the wife; we now look at the wife's hours of work. In this section we analyse the impact of the probability that a woman earns more than her husband in the hours of work offered in the labour market by the wife. 
In order to estimate the impact of the probability the wife earns more than her husband on the wife's working hours, we consider as the baseline specification an OLS model in which the dependent variable is the logarithm of hours offered per week:

$$
\begin{aligned}
& \text { HoursLS }_{i}=\beta_{0}+\beta_{1} \times \text { PrWifeEarnsMore } \\
& \beta_{3} \times X_{i}+\varepsilon_{i}
\end{aligned}
$$

where the control variables are the same as described in the previous model.

In the base model estimation in Table 3 , column 1 , the $\beta_{1}$ estimate is $-0.0158(p<0.01)$. The estimate of $\beta_{1}$ remains constant and statistically significant with the inclusion of the cubic of In HusbIncome and with a dummy for having a child, as can be seen in columns 2 and 3 , which show, respectively, estimates of $\beta_{1}$ with values $-0.0553(\phi<0.01)$ and $-0.0568(\phi<0.01)$. These results show that the probability of the wife earning more than her husband is inversely correlated with her working hours. This corroborates our hypothesis that women may prefer to offer fewer hours to the labour market when she is likely to earn more than her husband, in order to restore patterns of gender identity.

Table 3: Relative income and wife's working hours

\begin{tabular}{lcccccc}
\hline Variables & $(1)$ & $(2)$ & $(3)$ & $(4)$ & $(5)$ & $(6)$ \\
& HourLS & HourLS & HourLS & HourLS & HourLS & HourLS \\
\hline PrWifeEarnsMore & $-0.0158^{\star \star \star}$ & $-0.0553^{* \star *}$ & $-0.0568^{* \star *}$ & $-0.604^{\star *}$ & $-0.0270^{\star \star \star}$ & $-0.474^{* \star \star}$ \\
& $(0.00219)$ & $(0.00298)$ & $(0.00298)$ & $(0.217)$ & $(0.00494)$ & $(0.00662)$ \\
Additional controls: & & & & & & \\
Cubic in In Husblncome & None & Yes & Yes & None & None & None \\
anyChild(ren) & None & None & Yes & None & None & None \\
Sample restriction? & None & None & None & 1991 & 2000 & 2010 \\
Observations & $2,172,485$ & $2,172,485$ & $2,172,485$ & 452,150 & 974,796 & 745,539 \\
R-squared & 0.789 & 0.789 & 0.790 & 0.301 & 0.140 & 0.750 \\
Mean of HourLS & 37.2 & 37.2 & 37.2 & 35.5 & 37.5 & 38.8 \\
\hline
\end{tabular}

Notes: robust standard errors in parentheses; ${ }^{* *} p<0.01,{ }^{* *} p<0.05,{ }^{*} p<0.1$.

Source: authors.

In columns 4, 5, and 6 we present estimates for $\beta_{1}$ for each year. Estimates vary over time, but they present the same signal and are statistically significant.

\subsection{Informality in the labour market}

In many developing countries, the adjustments in demand in labour markets are handled through informal jobs. Thus, engaging in informal work is an option a woman may pursue in order to maintain a position in the labour force while adhering to the social norm that a wife should not earn more than her husband. This framework can be particularly important in Brazil, where formal labour contracts are rigid and there is not much room for adjustments in the intensive margin. As such, the choice of entering informal markets results from the fact that it is not possible to adjust the number of hours worked under formal contracts.

In order to test for the relationship between relative income and informality, we continue to use Census data. However, due to the non-existence of information that allows us to characterize an informal job in 1991, we will use data from 2000 and 2010. 
The definition of informality in the labour market is an open question, as there are a number of options. In this paper we follow the most common definition for an informal worker in Brazil as someone that is an informal employee (that is, has employment without a formal labour contract, binding by the Labour Law), or someone that is self-employed (has an occupation working for herself) (Barros et al. 1993; Fernandes 1996; Ulyssea 2005).

As in the analysis from the previous subsection, we restrict our sample to married women and to couples with earned income greater than zero. We use the same specification from the previous regressions, except for the dependent variable, which is now a dummy that assumes the value 1 if the woman is in the informal market.

As our dependent variable is binary, the regression is estimated by a linear probability model. Thus, the equation is:

$$
\begin{aligned}
& \text { Informal }_{i}=\beta_{0}+\beta_{1} \times \text { PrWifeEarnsMore }_{i}+\beta_{2} \times \ln \text { HusbIncome }_{i}+\alpha \times w_{i}^{p}+ \\
& \beta_{3} \times X_{i}+\varepsilon_{i}
\end{aligned}
$$

In the aggregate of 2000 and 2010, and using the basic specification, the coefficient estimate $\beta_{1}$ is $0.233(p<0.01)$, (Table 4, column 1). This result implies that an increase of 10 p.p. in the independent variable 'probability of women earning more than men at home' implies an increase of 2.3 p.p. in the probability of a woman engaging in the informal labour market. As we introduce additional controls, the estimated $\beta_{1}$ declines to 0.174 , though it continues to be statistically significant $(p<0.01)$, as seen in columns 2 and 3 of Table 4 . In columns 4 and 5 we present estimates for $\beta_{1}$ for each year. Estimates present the same signal and are statistically significant: $\beta_{1}$ equals $0.077(p<0.01)$ and $0.185(p<0.01)$ for 2000 and 2010, respectively.

Table 4: Relative income and informality

\begin{tabular}{lccccc}
\hline Variables & $\begin{array}{c}(1) \\
\text { Informal }\end{array}$ & $\begin{array}{c}(2) \\
\text { Informal }\end{array}$ & $\begin{array}{c}(3) \\
\text { Informal }\end{array}$ & $\begin{array}{c}(4) \\
\text { Informal }\end{array}$ & $\begin{array}{c}(5) \\
\text { Informal }\end{array}$ \\
\hline PrWifeEarnsMore1 & $0233^{* * *}$ & $0.174^{* * *}$ & $0.174^{* * *}$ & $0.0775^{* * *}$ & $0.185^{* * *}$ \\
& $(0.0031)$ & $(0.0036)$ & $(0.0036)$ & $(0.0054)$ & $(0.0054)$ \\
Observations & $1,586,816$ & $1,586,816$ & $1,586,816$ & 868,851 & 717,965 \\
R-squared & 0.112 & 0.112 & 0.113 & 0.103 & 0.129 \\
Additional controls: & None & Yes & Yes & Yes & Yes \\
Cubic in In Husblncome & & & & & \\
anyChild(ren) & None & None & Yes & Yes & Yes \\
Sample restriction & None & None & None & 2000 & 2010 \\
Mean of Informal & 0.48 & 0.48 & 0.48 & 0.48 & 0.47 \\
\hline
\end{tabular}

Notes: robust standard errors in parentheses; ${ }^{\star * *} p<0.01,{ }^{* *} p<0.05,{ }^{*} p<0.1$.

The PrWifeEarnsMore1 is based on the distribution of the wife's actual earnings.

Source: authors.

\section{Robustness test}

In assessing the role of gender identity in the marriage and labour markets, we have followed Bertrand et al. (2015) in the definition of the relevant social prescription related to gender roles in the marriage. However, what if the relevant social norm is that 'women are 
responsible for child-rearing, while men are providers' instead of the social prescription analysed in this paper? ${ }^{12}$

In order to account for this possibility of 'asking the wrong question', we analyse whether the results found in the previous section are robust to splitting the sample between women with and without children. If it is only the social norm on child-rearing that matters, we should find different results when analysing women without children.

In Table 5 we estimate the three models related to labour market decisions separately for the two groups of women: with and without children. Remarkably, results for married women without children are stronger than for women with children. In columns 1 and 2, results on the effects on labour force participation remain negative and robust for women with and without children: -0.130 and -0.166 , respectively. Regarding the effects on the wage gap, the $\beta_{1}$ estimated for women without children is almost twice the $\beta_{1}$ estimated for women with children, which can be seen in columns 3 and 4 . In columns 5 and 6 are presented the results of the model of the impact of the probability of the wife earning more than her husband on the wife's hours of work for women without children and women with children; in both cases the $\beta_{1}$ estimation also has negative signals. Finally, columns 7 and 8 present results for participation in the informal labour market. Again, results are stronger for women without children.

12 The World Values Survey has a question on that issue too: 'When a mother works for pay, the children suffer.' 
Table 5: Robustness tests-relative income and labour market outcomes for women with and without children

\begin{tabular}{|c|c|c|c|c|c|c|c|c|}
\hline Variables & $\begin{array}{c}(1) \\
\text { wifeLFP }\end{array}$ & $\begin{array}{c}(2) \\
\text { wifeLFP }\end{array}$ & $\begin{array}{c}(3) \\
\text { WageGap }\end{array}$ & $\begin{array}{c}(4) \\
\text { WageGap }\end{array}$ & $\begin{array}{c}(5) \\
\text { HourLS }\end{array}$ & $\begin{array}{c}(6) \\
\text { HourLS }\end{array}$ & $\begin{array}{c}(7) \\
\text { Informal }\end{array}$ & $\begin{array}{c}(8) \\
\text { Informal }\end{array}$ \\
\hline PrWifeEarnsMore & $\begin{array}{c}-0.166^{\star * *} \\
(0.0055)\end{array}$ & $\begin{array}{c}-0.130^{\star * *} \\
(0.0019)\end{array}$ & $\begin{array}{c}-0.738^{\star * *} \\
(0.0225)\end{array}$ & $\begin{array}{c}-0.381^{\star * *} \\
(0.0577)\end{array}$ & $\begin{array}{c}-0.0851^{* * *} \\
(0.00388)\end{array}$ & $\begin{array}{c}-0.0134^{* * *} \\
(0.00469)\end{array}$ & $\begin{array}{l}0.181^{* * *} \\
(0.0093)\end{array}$ & $\begin{array}{l}0.171^{* * *} \\
(0.0039)\end{array}$ \\
\hline \multicolumn{9}{|l|}{ Additional controls: } \\
\hline Cubic in In Husblncome & Yes & Yes & Yes & Yes & Yes & Yes & Yes & Yes \\
\hline Sample restriction & No children & Children & No children & Children & No children & Children & No children & Children \\
\hline No Children & Children & & & & & & & \\
\hline Observations & 470,541 & $4,139,019$ & 282,471 & $1,718,818$ & & & 224,571 & $1,362,245$ \\
\hline R-squared & 0.172 & 0.136 & 0.02 & 0.07 & 0.731 & 0.789 & 0.08 & 0.11 \\
\hline Mean of WifeLFP & 0.53 & 0.36 & & & & & & \\
\hline Mean of WageGap & & & -0.398 & -0.4 & & & & \\
\hline Mean of Hours & & & & & 37.0 & 38.0 & & \\
\hline Mean of Informal & & & & & & & 0.37 & 0.49 \\
\hline
\end{tabular}

Notes: robust standard errors in parentheses. ${ }^{* \star} p<0.01,{ }^{* *} p<0.05,{ }^{*} p<0.1$.

Source: authors. 
Further research on these results is an interesting avenue to be explored. Nevertheless, as robustness tests, these results imply that when it comes to gender identity, social norms are not only related to child-rearing. It seems, indeed, to exist as a norm that women should not earn more than men, irrespective whether they have children.

\section{Conclusion}

This paper contributes to the literature on identity economics and gender inequality. More specifically, we extend the analysis proposed by Bertrand et al. (2015) to a developing country. Our results show that relative income distribution within households presents a pattern similar to that of the United States and Germany. In only 7 per cent of the couples in our sample does the wife earn more than her husband.

Regarding the results on the effects of the gender social norm on female labour supply, we verified that the odds of finding a woman in the labour market are lower when her probability of earning more than her husband is higher. In addition, contingent on being in the labour force, the gap between potential and actual wage is higher for women with higher probability of earning more than their husbands, and they offer fewer working hours in the labour market. Finally, different from previous studies, we show that a higher probability of earning more than her husband directs a woman towards the informal labour market, which is a specific feature of developing countries.

Therefore, this paper's results point to a significant weight of social norms related to gender identity in marriage formation and in female participation in the labour market.

The last 50 years have witnessed a substantial increase in opportunities for women, which led, indeed, to a reversal in the educational gap and a narrowing of the wage gap. Nevertheless, much gender inequality remains to be explained. In this context, concepts like gender identity and the social norms associated with $\mathrm{it}^{13}$ become crucial to understanding the remaining inequalities. Thus, in order to reduce gender inequality, it is necessary to achieve new social norms that affect the very notion of gender identity.

It is striking that this social norm is seen as unexceptional, not only in Brazil. This sheds light on the need to invest in recognition policies that can, by changing social norms, extend their effect to economic aspects, such as female participation in the labour market.

This paper has shown how gender identity potentially affects economic decisions among couples in Brazil; however, it is necessary to improve the analysis of the long-term determinants of gender identity and how market forces help shape it. Moreover, due to limitations related to our data sources, we did not analyse some potential relationships, such as the impact of gender social norms on divorce and in the labour division within households. Yet, our results show that the introduction of the concept of identity represents a research field with great potential to be further explored. Finally, when it comes to reducing gender inequality, the concept of identity allows us to design better, more effective public policies.

\footnotetext{
${ }^{13}$ Social norms are usually path dependent (Kranton 2016).
} 


\section{References}

Akerlof, G.A., and R.E. Kranton (2000). 'Economics and Identity'. Quarterly Journal of Economics, 3: 715-53.

Akerlof, G.A., and R.E. Kranton (2010). Identity Economics: How Identities Shape Our Work, $W$ ages, and Wellbeing. Princeton, NJ: Princeton University Press.

Altonji, J.G., T.E. Elder, and C.R. Taber (2005). 'Selection on Observed and Unobserved Variables: Assessing the Effectiveness of Catholic Schools'. Journal of Political Economy, 113(1): 151-84.

Barbosa, A.L.N.d.H. (2014). 'Participaticão Feminina no Mercado de Trabalho Brasileiro'. Technical Note. Brasilia: Ipea.

Barros, R.P., and R.S.P. Mendonça (1996). 'Diferenças Entre Discriminação Racial e por gênero e o Desenho de políticas Anti-discriminatorias'. Estudos Feministas, 4 (1): 183.

Barros, R., R. Mello, and V. Pero (1993). 'Informal Labor Contracts: a Solution or a Problem?' Ipea Discussion Paper 40. Brasilia: Ipea.

Becker, G.S. (1973). 'A Theory of Marriage: Part I'. The Journal of Political Economy, 81(4): 81346.

Beltrão, K.I., and J.E.D. Alves (2013). 'A Reversão do Hiato de gênero na Educação Brasileira no Século xx’. Cadernos de Pesquisa, 39 (136): 125-56.

Bertrand, M. (2011). 'New Perspectives on Gender'. In: D. Card and O. Ashenfelter (eds), Handbook of Labor Economics, vol. 4. New York: Elsevier.

Bertrand, M., E. Kamenica, and J. Pan (2015). 'Gender Identity and Relative Income Within Households'. The Quarterly Journal of Economics, 130(2): 571-614.

Cerqueira, D., A. Martins, and J. Junior (2015). 'Avaliando a Efetividade da lei Maria da Penha’. 'Technical Report. Brasilia: Instituto de Pesquisa Econômica Aplicada-IPEA.

Costa, J.S.D.M., A.L.N.D.H. Barbosa, G.I. Hirata, et al. (2016). 'Efeitos da Ampliação dos Direitos Trabalhistas Sobre a Formalização, Jornada de Trabalho e Salários das Empregadas Domésticas'. In Anais do XLIII Encontro Nacional de Economia [Proceedings of the 43rd Brazilian Economics Meeting]. Niterói: ANPEC-Associação Nacional dos Centros de Pósgraduação em Economia [Brazilian Association of Graduate Programs in Economics].

Fernandes, R. (1996). 'Mercado de Trabalho não-Regulamentado: Participa ção Relativa e Diferenciais de Salários'. Pesquisa e Planejamento Econômico, 26(3): 417-42.

Fraser, N. (1995). 'From Redistribution to Recognition? Dilemmas of Justice in a "postSocialist” Age'. New Left Review, 212: 68.

Goldin, C. (2014). 'A Grand Gender Convergence: Its Last Chapter'. The American Economic Review, 104(4): 1091-119.

Heckman, J.J. (1979). 'Sample Selection Bias as a Specification Error'. Econometrica: Journal of the Econometric Society, 47(1): 153-61.

Hederos Eriksson, K. and A. Stenberg (2015). 'Gender Identity and Relative Income Within Households: Evidence from Sweden’. Discussion Paper. Bonn: IZA. 
Hoffmann, R., A.M.H. Ometto, M.C. Alves, et al. (1999). 'Participação da Mulher no Mecado de Trabalho: Discriminação em Pernambuco e são Paulo'. Revista Brasileira de Economia, 53(3): 287-322.

Kranton, R.E. (2016). 'Identity Economics 2016: Where Do Social Distinctions and Norms Come From?' The American Economic Review, 106(5): 405-09.

Matos, R.S., and A.F. Machado (2006). 'Diferencial de Rendimento por cor e Sexo no Brasil (1987-2001)'. Econômica, 8(1): 5-27.

Murphy, K.M., and R.H. Topel (1990). 'Efficiency Wages Reconsidered: Theory and Evidence'. In Y. Weiss and G. Fishelson (eds), Advances in the Theory and Measurement of Unemployment. New York: Springer.

Pinheiro, L.S., A.T. Lima Junior, N.d.O. Fontoura, and R.d. Silva (2016). 'Mulheres e Trabalho: Breve Análise do Perído 2004-2014'. Technical Note. Brasilia: Ipea.

Stewart, F. (2005). 'Horizontal Inequalities: A Neglected Dimension of Development'. In A.B. Atkinson, K. Basu, J. Bhagwati, et al., WIDER Perspectives on Global Development. New York: Springer.

Ulyssea, G. (2005). 'Informalidade no Mercado de Trabalho Brasileiro: uma Resenha da Literatura'. Revista de Economia Política, 26(4). DOI: http://dx.doi.org/10.1590/S010131572006000400008 .

Wieber, A., and E. Holst (2015). 'Gender Identity and Women's Supply of Labor and NonMarket Work: Panel Data Evidence for Germany'. Discussion Paper. Berlin: DIW.

WVSA (2014). World Values Survey 2010-2014. Madrid: ASEP/JDS. 


\section{Appendix: marriage rates and relative income}

In Section 5 of the paper we showed that the distribution of relative income within households suggests that people avoid the situation in marriage in which the husband earns less than his wife. In this Appendix we present an econometric analysis that seeks to estimate how the share of individuals that are currently married varies with the probability that a woman earns more than a man.

Using the Brazilian Demographic Censuses of the IBGE for the years 1991, 2000, and 2010, we restrict the sample to individuals who are between 18 and 65 years old. We assign each individual to a marriage market based on the observed pattern that most marriages occur between people who are of the same race and of similar age and educational backgrounds (Becker 1973). Moreover, marriages usually occur between people who live near each other.

Accordingly, we define marriage markets based on: region of residence (North, Northeast, Southeast, South, and Midwest), race, age group, and educational group. We consider two races: white (white and yellow) and black (black, mixed race, and indigenous). The three age groups are: (1) 18-30 years for women and 18-32 for men; (2) 31-44 years and 33-46 years for women and men, respectively; and (3) 45-64 years for women and 47-66 years for men. The three groups of educational attainment are: (1) up to four years of education; (2) 5-10 years of schooling; and (3) $11+$ years of schooling. We made the combinations of each group and created 90 marriage markets.

We used the marriage market as our unit of analysis because, across the three years of analysis, 45 per cent of marriages occurred between individuals of the same marriage market. Besides that, people marry individuals with characteristics similar to their own: in Brazil, across all years, 73 per cent of marriages occurred among men and women of the same age group, 64 per cent occurred among people from the same educational group, and 73 per cent were between people of the same race.

Thus, given a particular marriage market, we want to know how changes in the relative income distribution among men and women affect marriage rates. For each marriage market $m$ and year $t \in[1991,2000,2010]$, we estimate the odds that a woman's income is greater than a man's income when we randomly combine a woman and a man. More specifically, given a woman $i$ and a man $j$, we consider a binary variable that takes a value of 1 if the income of $i$ exceeds that of $j$. We set PrWomanEarnsMore $m_{m}$ as the average of this binary variable in all possible couples. More precisely, we created 30,000 couples for each marriage market and year, joining, with replacement, randomly a woman with a man of that marriage market. Then we calculated the percentage of couples in which the woman earns more than the man.

In calculating PrWomanEarnsMore $m$, we considered several measures of income. First, we use the actual earnings of individuals, where we compute zero income for those that are not in the labour force. Then, we also use the total income of individuals, which, in addition to wage income, include capital income and transfers. Finally, we created a measure of expected income based on socioeconomic characteristics. For this, we use a wage estimation model with Heckman selection bias correction (Heckman 1979).

Throughout all Census years and marriage markets, the probability that a woman earns more than a man is 20 per cent. There was an increase in that probability over the years: the 
likelihood of a woman earning more than a man was 17 per cent in 1991 and increased to 25 per cent in 2010 .

Based on Bertrand et al. (2015), our baseline OLS specification is the following:

$$
\begin{aligned}
& \text { MaleMarried }_{m t}=\beta_{1} \times \text { PrWomanEarnsMore }_{m t}+\beta_{2} \times \ln \text { WomensIncome }_{m t}+ \\
& \beta_{3} \times \ln \text { MensIncome }_{m t}+\beta_{4} \times X_{m t}+\gamma_{t}+\gamma_{t} \times \text { AgeGroup }_{m}+\gamma_{t} \times \text { EduGroup }_{m}+ \\
& \gamma_{t} \times \text { Race }_{m}+\gamma_{t} \times \text { Region }_{m}+\alpha_{m}+\varepsilon_{m t}
\end{aligned}
$$

where the dependent variable is the proportion of married men in a given marriage market $m$ and year $t$. We estimated different probabilities that a woman earns more than a man, based on our three distinct measures of income. We add to the model $\ln W_{\text {omensIncomemt }}$ and In MensIncomemt, respectively, the logarithm of the average woman's and man's earnings in marriage market $m$ and year $t$. All specifications of the model include marriage market fixed effects $a_{m}$, year fixed effects $\gamma_{t}$, and the interaction of year fixed effects and age group, educational group, race, and region of residence. Besides that, each observation is weighted by the number of women in the marriage market that year.

We also included some additional controls: the sex ratio, ${ }^{14}$ average years of studies for men and women, and the number of men and women in the marriage market.

Column 1 of Table A1 presents our baseline specification, in which PrWomanEarnsMore $e_{m t}$ was estimated using the $\log$ of earnings per hour of individuals. The estimate of $\beta_{1}$ is 0.146 , but is not statistically significant. However, the inclusion of a set of additional controls, as presented in column 2 , drives the estimate of $\beta_{1}$ to become statistically significant $(p<0.01)$ and negative, with a value of -0.226 . This is a first indication that an increase in the likelihood of a woman earning more than a man reduces marriage formation.

In columns 3 and 4 we estimate PrWomanEarnsMore $m_{m}$ using the monthly earnings from the labour market. The estimate of $\beta_{1}$ for the first model specification, without additional controls, was $-0.278(p<0.01)$. When we add additional controls, the $\beta_{1}$ estimated becomes stronger: $-0.318(\phi<0.01)$.

We consider the same specification for columns 5 and 6 , but we use another measure of income to estimate PrWomanEarnsMoremi the total earnings. Both estimations of $\beta_{1}$ are statistically significant and the $\beta_{1}$ estimated becomes stronger when we include additional control variables, going from $-0.251(p<0.01)$ to $-0.296(p<0.01)$.

In columns 7 and 8 we use the predicted income, estimated using the Heckman selection model. The estimate $\beta_{1}$ on the first specification is -0.112 and is not statistically significant. When we add additional controls, the estimate of $\beta_{1}$ becomes statistically significant: -0.234 $(p<0.01)$.

\footnotetext{
${ }^{14}$ We define the sex ratio as the total number of men against the total number of women for determining marriage market $m$ and year $t$ according to the following formula:
}

$$
\text { Sex } \text { ratio }_{m} t=\frac{\text { TotalMan }_{m t}}{\text { TotalWomen }_{m t}}
$$


These results highlight the importance of relative income between men and women in the marriage market. Our model estimation presents evidence of a negative relationship between the probability that a woman earns more than a man and marriage rates. 
Table A1: Relative income and marriage rates: dependent variable $=$ MaleMarried

\begin{tabular}{|c|c|c|c|c|c|c|c|c|}
\hline Variables & $\begin{array}{c}\text { (i) } \\
\text { Actual }\end{array}$ & $\begin{array}{c}(2) \\
\text { Actual }\end{array}$ & $\begin{array}{c}(3) \\
\text { Actual }\end{array}$ & $\begin{array}{c}(4) \\
\text { Actual }\end{array}$ & $\begin{array}{l}(5) \\
\text { Total }\end{array}$ & $\begin{array}{l}(6) \\
\text { Total }\end{array}$ & $\begin{array}{c}(7) \\
\text { Predicted }\end{array}$ & $\begin{array}{c}(8) \\
\text { Predicted }\end{array}$ \\
\hline \multirow[t]{2}{*}{ PrWomanEarnsMore } & 0.147 & $0.226^{* * *}$ & $-0.273^{* *}$ & $-0.318^{* * *}$ & $-0.251^{* * *}$ & $-0.296^{\star * \star}$ & -0.112 & $-0.234^{* * *}$ \\
\hline & $(0.147)$ & $(0.110)$ & $(0.108)$ & $(0.0753)$ & $(0.105)$ & $(0.0711)$ & $(0.110)$ & $(0,0669)$ \\
\hline Observations & 270 & 270 & 270 & 270 & 270 & 270 & 270 & 270 \\
\hline R-squared & 0.964 & 0.985 & 0.965 & 0.986 & 0.965 & 0.986 & 0.964 & 0.985 \\
\hline \multicolumn{9}{|l|}{ Additional controls: } \\
\hline sexRatio & None & Yes & None & Yes & None & Yes & None & yes \\
\hline femaleAvgYearsOfEducation & None & Yes & None & Yes & None & Yes & None & yes \\
\hline maleAvgYearsOfEducation & None & Yes & None & Yes & None & Yes & None & yes \\
\hline numFemales & None & Yes & None & Yes & None & Yes & None & yes \\
\hline numMales & None & Yes & None & Yes & None & Yes & None & yes \\
\hline
\end{tabular}

Notes: robust standard errors in parentheses. ${ }^{* *} p<0.01,{ }^{* *} p<0.05,{ }^{*} p<0.1$.

Source: authors. 